\title{
Comparison of Magnetic Resonance Imaging and Mammography Images of Diagnosis of Breast Masses
}

\author{
Shivanand V. Patil ${ }^{1}$, Ravi Kumar Yeli ${ }^{2}$, Satish D. Patil ${ }^{1}$, Naga Babu Pyadala ${ }^{3}$ \\ ${ }^{1}$ Associate Professor Department of Radiology \& Imaging, B M Patil Medical Collage \& Research Centre, BLDE University \\ (DU), Vijayapur, Karnataka, ${ }^{2}$ Assistant Professor, Department of Radiology \& Imaging, B M Patil Medical Collage \& Research \\ Centre, BLDE University (DU), Vijayapur, Karnataka, ${ }^{3}$ Associate Professor, Department of Biochemistry, MNR Medical College \\ \& Hospital, Sangareddy, Telangana, India
}

Corresponding author: Dr. Ravi Kumar Yeli, Assistant Professor, Department of Radiology \& Imaging, Shri B M Patil Medical Collage \& Research Centre, BLDE University (DU), Ashram Road, Vijayapur, Karnataka - 586103, India

DOI: http://dx.doi.org/10.21276/ijcmsr.2020.5.2.21

How to cite this article: Shivanand V. Patil, Ravi Kumar Yeli, Satish D. Patil, Naga Babu Pyadala. Comparison of magnetic resonance imaging and mammography images of diagnosis of breast masses. International Journal of Contemporary Medicine Surgery and Radiology. 2020;5(2):B84-B87.

\section{A B S T R A C T}

Introduction: Breast cancer challenges whole health care system and second most common carcinoma in Indian women. The present study aimed to access the diagnostic accuracy of MRI in diagnosis of malignant features of the breast masses as compared to mammography findings.

Materials and methods: A total of 60 patients provisionally diagnosed as breast mass lesion were included in this study. The cytopathological techniques used for all the breast mass. MRI and mammography techniques performed for all patients.

Result: In total 60 patients, 45 were palpable and 15 were non-palpable masses. In case of palpable lesions, MRI and mammography showed high sensitivity $95 \%$ and $90 \%$ respectively. MRI reported $50 \%$ specificity as compared to mammography $30 \%$. For non-palpable cases, sensitivity of MRI was $90 \%$ as compared to mammography $70 \%$, while specificity of MRI was $50 \%$ and mammography showed $25 \%$ specificity.

Conclusion: In conclusion MRI showed better sensitivity and specificity in detection of breast cancer, which way it can reduce the unnecessary biopsies for doubtful palpable breast mass.

Keywords: Breast Mass, Palpable and Non-Plapable, Magnetic Resonance Imaging, Mammography, Cytopathology.

\section{INTRODUCTION}

Breast cancer id highly devastating and second most common cancer in Indian women. The National cancer registry project reported, 52,000 women develop breast cancer per year. ${ }^{1,2}$ In recent scenario, breast care is the biggest challenge for entire health care system. There are several risk factors associated with breast cancer are like, fibrocystic disease of breast, family history of breast cancer, previous personal history of breast cancer, elderly primi diminished lactation, nulliparity, late menopause, early menarche, huge exposure to ionizing radiation, history of cancer endometrium, colon or ovary etc. ${ }^{3,4,5}$ Therefore early detection of breast cancer is necessary for the better prognostic value. The main problems in breast cancer are lack of awareness, psychological reasons, fear of disease, which is the main cause of ignorance and hiding of the disease. These factors are creating breast cancer in its late stage. The previous study reported $90 \%$ of breast cancer diagnosed are in the stage II, III and IV. ${ }^{6}$ The breast cancer can be diagnosed discovery of breast mass either by patients or by mammography technique. In most of suspicious cases leads to be benign. ${ }^{78}$ Most of these patients are reffered to diagnosis of mammography, ultrasound, colour Doppler ultrasound, galactography, fine needle aspiration and in few cases with open surgical biopsy. ${ }^{9,10}$ All these above radiological techniques has low specificity which leads to unnecessary testing of benign cases in results anxiety for patients and excess cost in health care. ${ }^{11,12}$ Hence, there is need of highly specific radiological diagnosis to reduce the number of unnecessary diagnostic test. The mammography is the most widely used method, especially accurate for nonpalpable carcinoma. ${ }^{13,14}$ The mammography has low positive predictive value, hence it is not useful for the patients younger than 50 years age and in palpable breast carcinoma. ${ }^{14,15,16}$ This turns to excessive unnecessary biopsies without proof of malignancy. Other methods used to detect breast cancer are like ultrasound, colour Doppler ultrasound, mammography and magnetic resonance imaging. ${ }^{17} \mathrm{MRI}$ has proven to be useful method for detection of breast cancer, due to its ability to imaging excellent soft tissue contrast. The sensitivity of MRI higher as compared to mammography technique. ${ }^{19,20}$ The contrast enhanced MRI and dynamic MRI found to be more accurate in diagnosis of malignancy and also it can differentiate malignancy versus scarring and implants. Therefore the present study aimed to evaluate the diagnostic accuracy of MRI and mammography in the detection of malignant feature of breast masses. 


\section{MATERIAL AND METHODS}

A total of 60 clinically suspected patients were studied. Out of total, 45 patients had palpable mass and 15 patients had non palpable mass. 40 patients were of above 50 years age and the remaining 20 patients below 50 years age group. This study was conducted in Department of Radiology, B M Patil Medical Collage \& Research Centre, Vijayapur, Karnataka, during the period of 2 years from March 2018 to February 2020. All patients gone through clinical examination with mammography, MRI and ultrasound examination. Informed consent was collected from all patients included in this study. The MRI study of both breasts done with 1.5 T MR system (Magnetom Vision, Seimens Medical System) and dedicated double breast coil. MRI diagnosis was performed with breasts were placed firmly by using cushions of different sizes inserted in the coil openings to minimize motion artefacts. After MRI study, fine needle aspiration was done for palpable breast mass and stereotactic biopsy was performed in case of non palpable masses. The aspirated and biopsied materials were examined for cytopathological findings.

\section{RESULTS}

A total of 60 clinically suspected patients were studied. Out of total, 45 patients had palpable mass and 15 patients had non palpable mass [Table 2]. 40 patients were of above 50 years age and the remaining 20 patients below 50 years age group [Table 1]. Breast cancer was confirmed in 20 cases by cytopathology. 15 of these cancers were palpable with size varies from $10 \mathrm{~mm}$ to $80 \mathrm{~mm}$. Mammography was reported 12 cancers of the breast and MRI was able to diagnose 18 cases. MRI showed false negative scans in 2 ductal carcinomas with diameters of $8 \mathrm{~mm}$ and $9 \mathrm{~mm}$. In both of above patients mammography results were doubtful but the malignancy not diagnosed by mammography or ultrasound. In three cases mammography and ultrasound results were

\begin{tabular}{|l|c|}
\hline Age group & Total number \\
\hline$<50$ years & 20 \\
\hline$>50$ years & 40 \\
\hline \multicolumn{2}{|c|}{ Table-1: Age group distribution in patients with breast mass } \\
$(n=60)$
\end{tabular}

\begin{tabular}{|l|c|}
\hline Category & Total number \\
\hline Palpable mass & 45 \\
\hline Non palpable mass & 15 \\
\hline Table-2: Characteristics of breast masses in patients $(n=60)$ \\
\hline
\end{tabular}

\begin{tabular}{|l|c|c|}
\hline Methods with category of lesions & Sensitivity & Specificity \\
\hline $\begin{array}{l}\text { Mammography with palpable } \\
\text { lesions }\end{array}$ & $90 \%$ & $30 \%$ \\
\hline $\begin{array}{l}\text { Mammography with non palpable } \\
\text { lesions }\end{array}$ & $70 \%$ & $25 \%$ \\
\hline MRI with palpable lesions & $95 \%$ & $50 \%$ \\
\hline MRI with non palpable lesions & $90 \%$ & $50 \%$ \\
\hline $\begin{array}{l}\text { Table-3: The sensitivity and specificity of mammography and } \\
\text { MRI for the diagnosis of breast mass lesions }\end{array}$ \\
\hline
\end{tabular}

showed negative. But because of clinical examinations and family history of breast cancer the patients were examined by both non contrast and contrast enhanced MRI. In 1 case mammography showed asymmetric density of breast tissue but MRI reported diffuse contrast enhancement of low intensity. Mammography and ultrasound did not show intra-ductal tumour growths. But MRI reported 4 cases. In case of palpable lesions, MRI and mammography showed high sensitivity $95 \%$ and $90 \%$ respectively. MRI reported 50\% specificity as compared to mammography $30 \%$. For non-palpable cases, sensitivity of MRI was $90 \%$ as compared to mammography $70 \%$, while specificity of MRI was $50 \%$ and mammography showed $25 \%$ specificity [Table 3].

\section{DISCUSSION}

The breast masses can be frequently examined by mammography technique. It is necessary to differentiate the mass lesions correctly so it's easy to differentiate between benign and malignant lesions. The widely used method to diagnose breast mass is mammography, which has diagnostic sensitivity of $85-95 \% .^{8,11-13}$ But due to its low diagnostic specificity, there is need to do additional diagnostic procedures. ${ }^{12,21}$ Usually younger women has denser breast, also use of oestrogen replacement therapy increases the breast density during or closely after the beginning of menopause. The mammography method has lower sensitivity to diagnose dense breast parenchyma and younger age group. ${ }^{22-24}$ Recently to diagnose breast mass, non invasive procedures like, MRI, colour Doppler ultrasound, and ultrasound are additional diagnostic methods. Although non invasive methods are available to diagnose breast masses, but in certain cases biopsies and fine needle aspiration are necessary to obtain reliable results. ${ }^{10,11,25}$ The breast cancer cases are related to tumour angiogenesis. The increased blood vessels can increase the vascular permeability, which increase tumour blood volume leads to arteriovenous shunt formation, altered capillary bed transmit time, increased interstitial pressure due to absent lymphatic vessels in tumours result form tumour angiogenesis and create characteristic patterns of intravenously injected contrast medium that can be differentiated from those related to benign lesions. ${ }^{2,26-28}$ In this study the sensitivity was higher for MRI than mammography. But the specificity showed lower for both MRI and mammography as per our study. Most of the cases mammography did not distinguish between benign and malignant lesions, also MRI not provided any additional information for these cases. Although some studies reported good specificity of MRI, and few studies showed MRI specificity ranges between 30-70\%. ${ }^{19,25,29,30}$ Our study reported low specificity of MRI for the diagnosis of breast mass. In our study both mammography and MRI reported higher diagnostic sensitivity to examine palpable breast masses (95\% and 90\% respectively). In case of non palpable breast mass, MRI showed higher sensitivity than mammography i.e. $90 \%$ and $70 \%$ respectively. In case of benign breast mass, mammography and MRI both reported $50 \%$ false positive results. One most important limitation 
of mammography method are the dense breasts resulting from changes during menstrual cycle, fibrocystic changes, lactation and oestrogen replacement therapy. In case of MRI, its has limitation like, long repetition time which does not optimize the T1 weighted images. ${ }^{28,31}$ In conclusion MRI showed better sensitivity and specificity in detection of breast cancer than mammography, which way it can reduce the unnecessary biopsies for doubtful palpable breast mass.

\section{ACKNOWLEDGEMENT}

The authors are thankful to Director and Dean of B M Patil Medical Collage \& Research Centre, for their valuable support during the study period.

\section{REFERENCES}

1. Annual report, 1984. National cancer registry. A project of Indian council of medical research, New Delhi 1987.

2. National cancer registry programme, Biennial report 1988-1989, An epidemiological study, Indian council of medical research, New Delhi 1992.

3. Farewell VT, Bulbrook RD, Hayward JL. Risk factors in breast cancer: A prospective study in the island of Gnernsy, in early diagnosis of Breast cancer. New York: E. Grandmann and L. Beck Gustav Fisher verlag Stuttgart, 1978: 43-51, 1978.

4. The breast cancer digest. US deptt. of Health, Education and welfare. Public health service, NIH, National cancer Institute, Bethesda, Maryland - 202201. NIH Publication, 1979: 80 - 1691.

5. Nair MK, Sankaranarayanan R, Nair KS, etal. Overall survival from breast cancer in Kerala, India, in relation to the menstrual, reproductive and clinical factors. Cancer 1993; 71(1): 1791 - 6.

6. Schmitt EL, Threatt B. Characteristics of breast cancer in an incident cancer population. AJR 1984; 143(4): 402 $-406$.

7. Baker LH. Breast cancer detection demonstration project: five year summary report. CA Cancer J Cline 1982; 32(6): 194 - 225.

8. Verbeek AL, Hendriks JH, Holland R, Marvunac M, Sturmans F, Day NE. Reduction of breast cancer mortality through mass screening with modern mammography: first results of the Nijmegen project, 1975 - 1981. Lancet 1984; 1(1): 1222 - 1224.

9. Jackson VP. The role of ultrasound in breast imaging. Radiology 1990; 177(3): 305 - 309.

10. Jackman RJ, Nowels KW, Shepard MJ, Finkelstein SL, Marzoni FA. Sterotaxic large - core needle biopsy of 450 nonpalpable breast lesions with surgical correlation in lesions with cancer or atypical hyperplasia. Radiology 1994; 193(5): 91 - 95.

11. Hermann G. Janus C. Schwartz IS, Krivisky B. Bier S, Rabinowitz JG. Nonpalpable breast lesions: accuracy of prebiopsy mammographic diagnosis. Radiology 1987; 165(2): 323 - 226.

12. Robertson CL. A private breast imaging practice: medical audit of 25, 788 screening and 1,077 diagnostic examinations, Radiology 1993; 187(4): 75 - 79.

13. Ciatto S, Cataliotti L, Distante V. Nonpalpable lesions detected with mammography: review of 512 consecutive cases. Radiology 1987; 165(6): 99 - 102.

14. Kopans DB. Positive predictive value of mammography. AJR 1992; 158(1): 521 - 526.

15. Coveney EC, Geraghty JG, O'Laoide R, Hourihane JB, O'Higgins NJ. Reasons underlying negative mammography in patients with palpable breast cancer. Cline Radiol 1994; 49(5): 123 - 125.

16. Lannin DR, Harris RP, Swanson FH, Edwards MS, Swanson MS, pories WJ. Difficulties in diagnosis of carcinoma of the breast in patients less than fifty year of age. Surg Gynecol Obstet 1993; 177(2): 123 - 126.

17. Khalkhali I, Cutrone JA, Mena I, et al. The usefulness of scintimammography (SMM) in patients with dense breasts on mammogram [abstract]. J Nucl Med, 1995; 36(4): 52.

18. Madjar H, Makowiec U, Mundinger A, Du Bois A, Kommoss F, Schillinger H. Value of high resolution sonography in breast cancer screening. Ultraschall Med, 1994; 15(6): 20 - 23.

19. Harms Se, Flaming DP, Hesley KL, et al. MR imaging of the breast with rotating delivery of excitation off resonance. Clinical experience with pathological correlation. Radiology 1993; 187(1): 493 - 501.

20. Flickinger FW, Allison JD, Sherry RM, et al. Differentiation of benign from malignant breast masses by time - intensity evaluation of contrast enhanced MRI. Magnetic Resonance Imaging 1993; 11(5): 617 -620 .

21. Kopans DB. What is a useful adjunct to mammography? Radiology 1986; 161(3): 560 - 561.

22. Joensuu H, Asola R, Holli K, Kumpulainen E, Nikkanen V, Parvinen LM. Delayed diagnosis and large size of breast cancer after a flase negative mammogram. Eur J Cancer 1994; 30(6): 1299 - 1302.

23. Kerlikowske K, Grady D, Barclay J, Sickles EA, Ernster $\mathrm{V}$. Effect of age, breast density, and family history on the sensitivity of first screening mammography. JAMA 1996; 276(2): 38.

24. Bird RE, Wallace TW, Yankaskas BC. Analysis of cancers missed at screening mammography. Radiology 1992; 184(4): 613 - 617.

25. Orel SG, Schnall MD, Livolsi VA, Troupin RH. Suspicious breast lesion: MRI with radiologic pathologic correlation. Radiology 1994; 190(5): 485 493.

26. Buadu LD, Murakami J, Murayama S, et al. Breast lesions: correlation of contrast medium enhancement patterns on MR images with histopathologic findings and tumour angiogenesis. Radiology 1996; 200(4): 639 -649 .

27. Tofts PS, Berkowitz B, Schnall MD. Quantitative analysis of dynamic Gd - DTPA enhancement in breast tumours using a permeability model. Magnetic Resonance Imaging 1995; 33(1): 564 - 568.

28. Muller - Schimpfle M, Ohmenhauser K, Sand J, et al. Dynamic 3D - MR mammography: is there a benefit of sophisticated evaluation of enhancement curves for clinical routine ? JMRI 1997; 7(6): 236 - 240.

29. Kaiser MA. MR Mammography. Radiology 1993; 33: $292-299$ 
30. Heywang SH, Wolf A, Pruss E, Hilbertz T. Eiermann W. Permanetter W. MR imaging of the breast with Gd - DTPA: use and limitations. Radiology 1989; 171(1): $95-103$.

31. Yang Y, Glover GH, Van Geleren P, et al. Fast 3D functional magnetic resonance imaging at $1.5 \mathrm{~T}$ with spiral acquisition. Magnetic Resonance Imaging 1996; 36(4): $620-626$.

Source of Support: Nil; Conflict of Interest: None

Submitted: 15-04-2020; Accepted: 17-05-2020; Published online: 26-06-2020 